\title{
OS MODELOS DE OFERTA DA EDUCAÇÃO EM PRISÕES NO BRASIL E A CONSTRUÇÃO DO SEU PROJETO POLÍTICO PEDAGÓGICO
}

\author{
Roberto da Silva ${ }^{l}$ \\ Universidade de São Paulo \\ http://orcid.org/0000-0001-8195-8664 \\ Marineila Aparecida Marques ${ }^{2}$ \\ Secretaria Estadual de Educação do Estado de São Paulo \\ http://orcid.org/0000-0002-3842-0401
}

\begin{abstract}
RESUMO:
A aprovação das Diretrizes Nacionais para a Oferta da Educação em Estabelecimentos Penais em 2009 abriu o caminho para a discussão em torno da pertinência de um projeto político pedagógico para o sistema penitenciário brasileiro, assentado nos dispositivos da Lei de Diretrizes e Bases da Educação e da Lei de Execução Penal. Nesse sentido o projeto político pedagógico - PPP, das prisões possibilita a salutar complementaridade entre a legislação educacional e penal, favorece a articulação entre políticas setoriais, potencializa a sinergia entre as ciências pedagógicas e jurídicas e mobiliza distintos campos profissionais em torno de objetivos comuns. Tomando a Pedagogia Social como a sua inspiração teórica, o artigo explora a legislação e a produção teórica do GEPÊPRIVAÇÃO (Grupo de Estudos e Pesquisas sobre Educação em Regimes de Privação da Liberdade) para discutir os modelos de oferta da Educação em prisões no Brasil, as potencialidades da Educação para impactar positivamente a Execução \Penal, aponta os avanços e retrocessos na política criminal e penitenciária e conclui pela potencialização das prerrogativas que a LDB concede à Educação de Jovens e Adultos para a construção de um Projeto Político Pedagógico para a Educação em prisões no Brasil que atenda às determinações da Resolução $\mathrm{CNE} /$ CEB n ${ }^{\circ} 3$, de 15 de Junho de 2010.
\end{abstract}

Palavras Chave: Diretrizes Nacionais. Projeto Político Pedagógico. Educação em Prisões.

\section{ABSTRACT:}

\section{THE SUPPLY MODELS OF PRISON EDUCATION IN BRAZIL AND THE CONSTRUCTION OF ITS POLITICAL PEDAGOGICAL PROJECT}

The approval of the National Guidelines for the Offer of Education in Penal Establishments in 2009, paved the way for the discussion around the pertinence of a political pedagogical project for the Brazilian prison system, based on the provisions of the Law of Directives and Bases of Education and the Penal Execution Law. In this sense, the political pedagogical project - PPP, of the prisons enables the healthy complementarity between the educational and penal legislation, favors the articulation between sectorial policies, enhances the synergy between the pedagogical and legal sciences and mobilizes different professional fields around common objectives. Taking Social Pedagogy as its theoretical inspiration, the article explores the legislation and the theoretical production of GEPÊPRIVAÇÃO (Group of Studies and Research on Education in Deprivation of Liberty) to discuss the models of education provision in

\footnotetext{
1 Doutor em Educação (USP). Professor Livre Docente da Pós-Graduação em Educação (USP). Coordenador do Grupo de Estudos e Pesquisas sobre Educação em Regimes de Privação da Liberdade (GEPÊPRIVAÇÃO). E-mail:kalil@usp.br

2 Mestranda do Programa de Pós-Graduação em Educação (USP). Supervisora de Ensino junto à Diretoria de Ensino da Região Centro Oeste, da Secretaria Estadual de Educação do Estado de São Paulo. E-mail: marineila@usp.br
} 
prisons in Brazil, the Education's potential to positively impact Criminal Execution, points out the advances and setbacks in criminal and penitentiary policy and concludes by strengthening the prerogatives that LDB grants to Youth and Adult Education for the construction of a Political Pedagogical Project for Education in prisons in Brazil that meets the provisions of Resolution CNE / CEB n ${ }^{\circ}$ 3, of June 15, 2010.

Keywords: National Guidelines. Pedagogical Political Project. Education in Prisons.

\section{RESUMEN:}

\section{LOS MODELOS DE OFERTA DE EDUCACIÓN PENITENCIARIA EN BRASIL Y LA CONSTRUCCIÓN DE SU PROYECTO POLÍTICO PEDAGÓGICO}

La aprobación de los Lineamientos Nacionales para la Oferta Educativa en Establecimientos Penales en 2009, abrió el camino para la discusión en torno a la pertinencia de un proyecto político pedagógico para el sistema penitenciario brasileño, basado en las disposiciones de la Ley de Directrices y Bases de Educación y la Ley de Ejecución Penal. En este sentido, el proyecto político pedagógico - PPP, de las cárceles posibilita la sana complementariedad entre la legislación educativa y penal, favorece la articulación entre políticas sectoriales, potencia la sinergia entre las ciencias pedagógicas y jurídicas y moviliza diferentes campos profesionales en torno a objetivos comunes. Tomando como inspiración teórica la Pedagogía Social, el artículo explora la legislación y la producción teórica del GEPÊPRIVAÇÃO (Grupo de Estudios e Investigaciones sobre Educación en Privación de Libertad) para discutir los modelos de provisión de educación en las cárceles en Brasil, el El potencial de la educación para impactar positivamente la Ejecución Penal, señala los avances y retrocesos en la política penal y penitenciaria y concluye fortaleciendo las prerrogativas que otorga LDB a la Educación de Jóvenes y Adultos para la construcción de un Proyecto Político Pedagógico para la Educación en las cárceles. en Brasil que cumple con las disposiciones de la Resolución CNE / CEB nº 3, de 15 de junio de 2010.

Palabras clave: Lineamientos nacionales. Proyecto Político Pedagógico. Educación en las Cárceles.

\section{Introdução}

A conveniência de discutir um projeto político pedagógico para o sistema penitenciário brasileiro decorre da aprovação das Diretrizes Nacionais para a Oferta da Educação em Estabelecimentos Penais, aprovada pela Resolução No 3, de 11 de março de 2009, do CNPCP e homologado pelo Ministério da Educação por meio da Resolução CNE nº 2, de 19 de Maio de 2010.

A implantação das Diretrizes Nacionais para a oferta da Educação em Estabelecimentos Penais no Brasil é orientada por três eixos que envolvem, de forma articulada, o sistema público de ensino e a Execução Penal, seja por meio dos ministérios da Educação e da Justiça, seja por meio das ações entre secretarias da Educação e da Administração Penitenciária ou equivalente nos estados.

O Eixo A (Gestão, Articulação e Mobilização) orienta a formulação, execução e monitoramento da política pública para a educação nas prisões, inclusive com a participação da sociedade civil, prática coletiva comum na seara da Educação, mas nova para a administração penitenciária e a execução penal. 
O Eixo B (Formação e valorização dos profissionais envolvidos na oferta) indica que a Educação nas prisões deve atender, além das óbvias necessidades dos presos, as necessidades de formação continuada e permanente de educadores, agentes penitenciários e operadores da Execução Penal.

O Eixo C (Aspectos pedagógicos) impõe aos estados a obrigatoriedade da criação de seus próprios projetos políticos pedagógicos, com base nos fundamentos conceituais e legais da Educação de Jovens e Adultos, bem como os paradigmas da educação popular, calcada nos princípios da autonomia e da emancipação dos sujeitos do processo educativo.

Como se depreende da análise destes três eixos e do conjunto das Diretrizes, o PPP das prisões possui uma dimensão orgânica e estruturante para as ações de múltiplos atores (projeto); impacta a Execução Penal, os procedimentos disciplinares e a rotina prisional (político); e organiza as condições de ensino, o tempo, o espaço e o currículo (pedagógico).

Como a mais nova fronteira da Educação, o PPP das prisões possibilita a salutar complementaridade entre a legislação educacional e legislação penal - LDB (BRASIL, 1996) e Lei de Execução Penal (BRASIL, 1984) -, favorece a articulação entre políticas setoriais - Educação, Trabalho, Saúde, Segurança Pública e Serviço Social -, potencializa a sinergia entre duas ciências - Pedagogia e Direito Penitenciário - e mobiliza distintos campos profissionais - professores e agentes penitenciários - em torno de objetivos comuns.

Por meio do Decreto ${ }^{\circ}$ 7.626, de 2011, foi promulgado o Plano Estratégico de Educação no Âmbito do Sistema Prisional, por meio do qual se impôs a todos os estados brasileiros a obrigatoriedade de construírem o seu Plano Estadual de Educação nas Prisões, de onde emerge, implícita ou explicitamente o projeto político pedagógico.

O Artigo 10 da Resolução CNE/CEB n 2, de 19 de maio de 2010 define que, As atividades laborais e artístico-culturais deverão ser reconhecidas e valorizadas como elementos formativos integrados à oferta de educação, podendo ser contempladas no projeto político-pedagógico como atividades curriculares, desde que devidamente fundamentadas (grifo nosso).

A prática observada no estado de São Paulo para construção do projeto político pedagógico constitui um parâmetro seguido por todos os demais estados brasileiros, ou seja, existe uma Norma Regimentais Básica para as Escolas Estaduais, que faz uma série de recomendações e dá orientações para quanto à elaboração di projeto político pedagógico e do regimento escolar, que deverá ser validado por uma instância do sistema de ensino, tal como uma Diretoria de Ensino.

O Artigo $1^{\circ}$ das Normas Regimentais do Estado de São Paulo para as escolas estaduais As escolas mantidas pelo Poder Público Estadual e administradas pela Secretaria de Estado da Educação, com base nos dispositivos constitucionais 
vigentes, na Lei de Diretrizes e Bases da Educação Nacional e no Estatuto da Criança e do Adolescente, respeitadas as normas regimentais básicas aqui estabelecidas, reger-se-ão por regimento próprio a ser elaborado pela unidade escolar (Grifo nosso).

O Artigo 84 da mesma norma reforça que "Incorporam-se a estas normas e ao regimento de cada escola estadual as determinações supervenientes oriundas de disposições legais ou de normas baixadas pelos órgãos competentes".

Isso quer dizer que entre 70 e $80 \%$ do projeto pedagógico de uma escola é previamente prescrito pelo respectivo sistema de ensino, ficando entre 20 e $30 \%$ para atendimento a especificidades locais e para cumprimento pró-forma dos artigos 14 e15 da LDBN que atribuem relativo grau de autonomia administrativa, pedagógica e financeira à unidade escolar.

São mais de 226 mil escolas nos 26 estados e Distrito Federal (INEPDATA, 2019) organizadas segundo esta mesma lógica e precisamos desta referência para entendermos a forma de elaboração do Projeto Político Pedagógico para a Educação em Prisões no Brasil.

Sendo o sistema prisional de responsabilidade predominantemente dos estados federados, a oferta da Educação para as pessoas privadas da liberdade e efetivada por uma diversidade de modelos em cada estado brasileiro, conforme se verifica no quadro a seguir.

\section{Quadro 1.}

\begin{tabular}{|l|l|l|}
\hline MODELO DE OFERTA & \multicolumn{1}{|c|}{ ESTADO } & \multicolumn{1}{c|}{ CARACTERÍSTICAS } \\
\hline $\begin{array}{l}\text { Escola de Referência ou } \\
\text { Escola Vinculadora }\end{array}$ & $\begin{array}{l}\text { Acre, Alagoas, Espírito } \\
\text { Santo, Minas Gerais, } \\
\text { Piaú, Rio Grande do } \\
\text { Norte, São Paulo, Ser- } \\
\text { gipe }\end{array}$ & $\begin{array}{l}\text { Trata-se de uma escola regular, sediada na comunidade, na qual são } \\
\text { lotados os professores que lecionam na prisão e matriculados pre- } \\
\text { sos e presas que queiram estudar. Esta escola faz todos os registros } \\
\text { escolares e emite a documentação escolar necessária. }\end{array}$ \\
\hline Escola Penitenciária & $\begin{array}{l}\text { Amapá, Amazonas, } \\
\text { Pernambuco, Rio de } \\
\text { Janeiro, Tocantins }\end{array}$ & $\begin{array}{l}\text { E o modelo mais antigo existente no Brasil, em que a Escola está si- } \\
\text { tuada dentro da unidade prisional, com toda sua estrutura e equipe. } \\
\text { Por determinação de lei elas tiveram que adotar nomes convencio- } \\
\text { nais para que a documentação escolar, certificados e diplomas não } \\
\text { identifiquem a Penitenciária como local de estudos. }\end{array}$ \\
\hline Anexos e Extensões & $\begin{array}{l}\text { Bahia, Goiás, Mara- } \\
\text { nhão, Roraima }\end{array}$ & $\begin{array}{l}\text { Trata-se de uma escola regular que mantem anexos e/ou extensões } \\
\text { em uma ou mais unidade prisionais. Professores, presos e presas } \\
\text { que estudam tem esta escola como referência para efeito de traba- } \\
\text { lho, matrícula e documentação escolar. }\end{array}$ \\
\hline CEEJA & $\begin{array}{l}\text { Ceará, Pará, Paraíba, } \\
\text { Paraná, Rio Grande do } \\
\text { Sul, Rondônia, Santa } \\
\text { Catarina }\end{array}$ & $\begin{array}{l}\text { Professores são vinculados a um Centro de Educação de Jovens } \\
\text { e Adultos, que também recebe a matrícula de presos e presas que } \\
\text { queiram estudar. }\end{array}$ \\
\hline $\begin{array}{l}\text { Distrito Federal, Mato } \\
\text { Grosso, Mato Grosso } \\
\text { do Sul }\end{array}$ & $\begin{array}{l}\text { Uma única escola (Centro Educacional 01 - DF), (Nova Chance } \\
\text {-MS) e Regina Bettini - MS) centraliza em todo o estado a vincu- } \\
\text { lação institucional de professores e a matrícula de todos os presos e } \\
\text { presas que estejam estudando. }\end{array}$ \\
\hline Escola Polo &
\end{tabular}

Fonte: Compilação do autor a partir dos Planos Estaduais de Educação em Prisões ${ }^{3}$. 
Por imposição da Resolução CNE/CEB n 2, de 2010, a Educação em prisões deve ser ofertada por profissionais do quadro regular do magistério, o que inibiu a atuação das fundações estaduais (FUNAP), que assumiam tais atribuições no Distrito Federal e no Estado de São Paulo.

Nos modelos referenciados acima, cada um apresenta suas vantagens e desvantagens, mas quando se considera do ponto e vista de um Projeto Político Pedagógico, é possível evidenciar algumas características.

As escolas de Referência, Vinculadoras e Certificadoras, por exemplo, tem um PPP para atendimento regular de seus alunos, de seus professores e de sua comunidade, mas ao atender a população prisional de sua vizinhança tem dificuldades em atender às especificidades deste novo público, proporcionar formação especializada para seus professores e de empregar material didático pedagógico apropriado para o contexto prisional.

A ausência de um quadro administrativo próprio para atender a prisão, inexistência de uma direção específica, de equipe pedagógica, de coordenação e de supervisão duplica o trabalho administrativo desta unidade escolar, com matrículas, rematrículas, transferências, controle de ponto e professores, registro de vida escolar e emissão de documentos. Impensável esta mesma escola lidar com dois PPPs, um para atendimento regular e outro para atendimento do sistema prisional.

A Escola Penitenciária, modelo mais antigo existente no Brasil, por estar instalada dentro de um complexo penitenciário, pode ter secretaria, sala de professores, biblioteca, direção própria, coordenação pedagógica, supervisão, quadro docente e quadro de apoio administrativo, podendo exercer bastante autonomia em relação a um PPP.

Em seu desfavor pesa a discussão semântica quanto à propriedade e pertinência do nome Escola Penitenciária, que pode sugerir uma prática pedagógica orientada para reforçar as praticas do encarceramento e de tudo o que isso pode significar, como a estigmatização, a submissão, o aprender a viver preso, além do fato de que a nomenclatura foi apropriada para se referir a uma instância de formação de pessoal penitenciário, hoje renomeada em alguns estados para Academia Penitenciária ou Escola de Administração Penitenciária.

Por força de imposição da legislação, as escolas penitenciárias precisaram alterar a nomenclatura, adotando nomes convencionais, para que a documentação escolar emitida em favor de seus alunos não contribuísse no processo de estigmatização com a identificação de Escola Penitenciária.

MJSP), Disponível em https://www.gov.br/depen/pt-br/acesso-a-informacao/acoes-e-programas/educacao-esporte-e-cultura/educacao-esporte-e-cultura. Consultado em 30 Out. 2020. 
O modelo de anexos e extensões é a própria expressão do tradicional puxadinho, espaço provisório e adaptado para sala de aula, sem qualquer infraestrutura de apoio à atividade docente.

A vinculação da Educação Prisional a um centro ou núcleo de Educação de Jovens e Adultos, quando este destinado exclusivamente à população presa apresenta mais vantagens do que desvantagens, dada a liberalidade que a LDB permite a esta modalidade de ensino e à flexibilidade que ela pode ter para atender segmentos específicos.

Deste que o centro ou núcleo tenha infraestrutura própria, direção, coordenação, supervisão, quadro docente, equipe de apoio administrativo, é possível ter e executar um PPP de maneira bastante razoável, proporcionando formação específica aos seus docentes e desenvolvendo material didático apropriado ao contexto prisional, além de poder realizar os exames de certificação e de aliar à Educação Básica a Educação Técnica e Profissional.

O modelo da Escola Polo, adotada no Distrito Federal, no Mato Grosso e Mato Grosso do Sul, dada a exclusividade do atendimento à população prisional, apresenta mais vantagens do que desvantagens na execução de um PPP próprio, pois tendo todos os elementos e insumos que conformam uma unidade escolar, pode orientar sua vocação integralmente para a Educação Prisional e tornar-se referência para a área no estado, inclusive para a formação inicial e continuada de seus docentes e no desenvolvimento e material didático pedagógico próprio e específico para este contexto.

Sua desvantagem mais saliente está na questão da logística, que faz com que a sede da escola esteja muito distante das unidades prisionais onde acontece a Educação.

\section{Condicionantes e determinantes do PPP da Educação em prisões}

Como a mais nova fronteira da Educação, contemplada no eixo epistemológico da Educação de Jovens e Adultos tal qual se pratica no Brasil, sob orientação do já antigo Parecer CFE $n^{0}$ 699/72, que atribui à EJA três funções básicas: reparadora, equalizadora e permanente ou qualificadora, a Educação em Prisões requer uma nova arquitetura pedagógica, com redefinição das atribuições dos profissionais que exercem a custódia da pessoa privada da liberdade e uma nova concertação entre as várias ciências que atuam no contexto prisional.

Em ensaios anteriores do GEPÊPRIVAÇÃO, Roberto da Silva e Fábio Aparecido Moreira apontaram que,

Muitos estudos, desde pesquisas acadêmicas, observações diretas por parte de educadores profissionais, relatórios produzidos por investigações judiciárias e parlamentares até monitoramentos realizados por entidades de defesa dos direitos humanos, assinalam que os programas educativos em estabelecimentos 
penitenciários são inadequados, de baixa qualidade e de pouca frequência por um único motivo: incompatibilidade entre os objetivos e metas da Educação e os objetivos e metas da pena e da prisão. (SILVA, MOREIRA, 2006, p. 12).

O título do artigo acima citado é Objetivos educacionais e objetivos da reabilitação penal: o diálogo possível, e este diálogo é revisitado agora à luz da Resolução CNE/CEB nº 2, de Maio de 2010, que no Inciso I do Artigo $3^{\circ}$ determina que "é atribuição do órgão responsável pela educação nos Estados e no Distrito Federal (Secretaria de Educação ou órgão equivalente) e deverá ser realizada em articulação com os órgãos responsáveis pela sua administração penitenciária".

Diante deste imperativo legal os mesmos autores acima referenciados advertem que

Esta incompatibilidade [acima citada] não é de ordem epistemológica, ainda que se possa afirmar que a condição de confinamento prolongado, a necessidade de rápida adaptação a um ambiente hostil marcado pela cultura da violência e a perda de referenciais de valor sejam capazes de suscitar outras formas de saberes e de produção de conhecimentos. [...] A incompatibilidade, diria eu, é de ordem conceitual. Enquanto prevalecer a concepção de prisão como espaço de confinamento, de castigo, de humilhação e de estigmatização social a Educação não terá lugar na terapia penal, limitando-se a ser, como efetivamente tem sido, apenas mais um recurso a serviço da administração penitenciária para ocupar o tempo ocioso de alguns poucos presos e evitar que se envolvam em confusões.

Isso quer dizer que precisamos dar eficácia ao princípio do regime de colaboração, tão enfaticamente colocado no artigo 211 da Constituição Federal de 1988, na Lei de Diretrizes e Bases da Educação Nacional (LDB), de 1996, nos Arranjos de Desenvolvimento da Educação (ADEs), na Resolução CNE/CEB 1, de 23 de janeiro de 2012, na Lei de Consórcios, de 6 de abril de 2005, no Decreto $\mathrm{n}^{\circ}$ 6.017, de 17 de janeiro de 2007, no artigo $7^{\circ}$ do Plano Nacional de Educação (PNE) (Lei n ${ }^{0}$ 13.005, de 25 de junho de 2014), que dizem: “A União, os Estados, o Distrito Federal e os municípios atuarão em regime de colaboração, visando ao alcance das metas e à implementação das estratégias objeto deste Plano.

Ora, a Educação é marcada pela intencionalidade e para isto se serve do espaço, do tempo, da progressividade dos conteúdos, do método, da didática, do controle e da avaliação e visa alcançar seus objetivos em médios e longos prazos e é preciso entender nesta nova arquitetura pedagógica as atribuições e competências dos entes nomeados na Resolução CNE/CEB que baliza este estudo.

Neste sentido, a atribuição do município na oferta da Educação em Prisões deveria ser na oferta da Educação de Jovens e Adultos, especialmente em relação à alfabetização e ao Ciclo I do Ensino Fundamental e não em relação à Educação Infantil, pois prisão não é lugar para crianças. 
A propósito, é oportuno a Educação se posicionar contrariamente à Lei $n^{\circ} 11.942$, de 2009, que alterou a Lei de Execução Penal (BRASIL, 1984) para instituir a "creche para abrigar crianças maiores de 6 (seis) meses e menores de 7 (sete) anos, com a finalidade de assistir a criança desamparada cuja responsável estiver presa." Esta lei é uma clara violação dos artigos $5^{\circ}$ e $6^{\circ}$ de outra lei $-8.069^{1} 90$ - o Estatuto da Criança e do Adolescente que assim determina

Art. $5^{\circ}$ Nenhuma criança ou adolescente será objeto de qualquer forma de negligência, discriminação, exploração, violência, crueldade e opressão, punido na forma da lei qualquer atentado, por ação ou omissão, aos seus direitos fundamentais.

Art. $6^{\circ} \mathrm{Na}$ interpretação desta Lei levar-se-ão em conta os fins sociais a que ela se dirige, as exigências do bem comum, os direitos e deveres individuais e coletivos, e a condição peculiar da criança e do adolescente como pessoas em desenvolvimento.

A Organização das Nações Unidas (ONU) aprovou em 14 de Dezembro de 1990 a Resolução nº. 45/110 intitulada Regras Mínimas para a Elaboração de Medidas não Privativas de Liberdade, também conhecida como Regras de Tóquio, orientando a todos os países a aplicação de sanções alternativas à prisão, reservando-se o encarceramento somente para atos de maior poder ofensivo ou para agentes que apresentem maior grau de periculosidade.

Segundo o espírito desta Resolução, o Brasil deveria encontrar urgentemente outras formas de responsabilização criminal da mulher sentenciada pelo cometimento de crimes que não seja o encarceramento. A concessão (SIC)da Lei no 11.942 para que a mulher possa ficar com seus filhos pequenos dentro da prisão durante o cumprimento da sentença só agrava o problema e impõe ao município uma atribuição que distorce suas finalidades originárias.

\section{Relação entre educação e execução penal e seus impactos}

Preliminarmente há que se lembrar que segundo o Artigo $3^{\circ}$ da Lei $n^{\circ} 7.210$ de 11 de Julho de 1984 “Ao condenado e ao internado serão assegurados todos os direitos não atingidos pela sentença ou pela lei”, logo impõe-se ao estado, suas agências e seus agentes a difícil tarefa de assegurar ao condenado a preservação de todos os seus demais direitos não atingidos pela sentença.

No meio jurídico ainda não há definições precisas e definitivas quanto à superveniência de um Direito Penitenciário ou de um Direito Educacional, que nos parece seria o campo adequado para a discussão quanto às intersecções entre o exercício do direito à Educação de pessoas privadas da liberdade e as regras da execução penal vigentes em estabelecimentos penais. 
Em dezembro de 2019, o Congresso Nacional aprovou a Emenda Constitucional 104 que instituiu a Polícia Penal como órgão responsável pela segurança dos estabelecimentos prisionais dos estados. A medida foi comemorada pelos sindicatos dos então denominados Agentes Penitenciários, mas lamentada pelas organizações de direitos humanos e pela Educação e por algumas razões bem simples.

Ainda que a categoria profissional e seus órgãos de representação tenham comemorado a iniciativa, para a Educação em Prisões isso significa um injustificável retrocesso, pois uma coisa é estender o Direito à Educação a agentes penitenciários civis que, de resto, tem as mesmas origens sociais e apresentam as mesmas necessidades educacionais dos presos sob sua responsabilidade. Outra coisa muito diferente é pensar a educabilidade social de pessoas fardadas, armadas, que são treinadas para obedecer ordens hierárquicas sem questioná-las e que, na nossa prática cotidiana, é a principal fonte de violação de direitos humanos no Brasil.

Na intersecção entre Educação e Execução Penal, entretanto, pode-se pensar em possíveis sinergias, interpenetrações e impactos positivos.

A segurança penitenciária, por exemplo, é sinônimo de altas muralhas, fossos no seu entorno, cães de vigilância e homens grandes e fortes armados até os dentes, com um só propósito: evitar a fuga do preso. Para a Educação, segurança advém de uma relação de confiança entre as partes, de reconhecimento da autoridade moral do professor e do desejo de ser conduzido pelos caminhos do conhecimento, da descoberta e da liberdade.

Reorganização do espaço físico. Nem todas as unidades prisionais possuem instalações próprias para escola ou alas de aulas, configurando um perímetro educacional. Entretanto, a possibilidade de se ter alas, raios, pavilhões ou módulos destinados aos presos que estudam pode se constituir em um diferencial desejável por parte dos presos, menos problemático para a administração penitenciária e mais humanizado do ponto de vista das relações humanas e sociais que se estabelecem no cárcere.

Transformar as assistências em Educação. Está definitivamente superado o paradigma assistencialista inscrito nos artigos 10 e 11 da Lei de Execução Penal e devem ser substituídos pelo paradigma da Educação patrimonial (I material), em Saúde, para os direitos (III -jurídica), para a cidadania (V - social) e para os valores (VI - religiosa), reorientando a atuação dos respectivos profissionais e de suas ciências para se colocarem a serviço da reabilitação do preso e não como meros sucedâneos da Justiça para a elaboração de laudos e pareceres.

Substituição da relação prêmio/castigo pela prevalência de direitos. Tudo na prisão é barganhável a partir desta relação: onde morar, quando trabalhar, as assistências, saídas tempo- 
rárias, visita íntima, acesso ao telefone, etc; em detrimento do exercício de legítimos direitos. A Educação não barganha nada e reconhece a cada um seus direitos proporcionalmente aos seus esforços, empenho e rendimento e não há quem não se felicite a sí próprio por ter vencido etapas na sua trajetória educacional.

Substituição da exploração da mão de obra pela profissionalização. O baixo nível de escolaridade e a baixa qualificação profissional da população prisional no Brasil é uma das razões da exploração da mão de obra do preso, com remuneração vergonhosa, sem direitos previdenciários e trabalhistas e em qualquer possibilidade de aproveitamento deste trabalho quando em liberdade. A Educação é fundamental para a qualificação desta mão de obra seja na tarefa da alfabetização, da elevação da escolaridade ou da profissionalização propriamente dita e é desejável que o preso esteja cursando o Ensino Médio, pelo menos, para que a profissionalização seja efetiva e possa representar a aquisição de uma profissão que possa ser exercida quando em liberdade.

Formação de lideranças positivas. Devemos superar a cultura de que a liderança na prisão seja exercida pelos mais fortes, mais violentos ou com maior coleção de crimes cometidos, nas quais prevalece o medo e o temos e não o respeito. A Educação é o meio para desenvolver a capacidade de análise de situação e de conjuntura, aprimorar a argumentação e fomentar o senso crítico necessário para a tomada de posturas e de decisões.

Progressão escolar como quesito de avaliação da terapia penal. Qual melhor indicador de sucesso na contemporaneidade do que a taxa de escolarização de uma pessoa ou de uma população? Quando se verifica a escolaridade inicial no momento da prisão e a escolaridade ao final do cumprimento da sentença pode-se ter um indicador preciso quanto ao aproveitamento do tempo de pena por parte do preso. A continuidade dos estudos em liberdade pode ser, inclusive, uma das condicionalidades para a progressão de regime, desde que de forma consensual e com os devidos acompanhamentos.

\section{O projeto político pedagógico para as prisões}

No livro Educação na Cidade (2001a), Paulo Freire, falando sobre sua experiência como secretário da Educação na cidade de São Paulo, apresenta sua concepção de construção de projeto político pedagógico:

Evidentemente, para nós a reformulação do currículo não pode ser algo feito, elaborado, pensado por uma dúzia de iluminados cujos resultados finais são encaminhados em forma de pacotes para serem executados de acordo ainda com as instruções e guias igualmente elaborados pelos iluminados. (FREIRE, 2001a, p. 24). 
A necessidade de um projeto político pedagógico pode ser entendida como decorrência direta do processo de maturidade democrática pelo qual o Brasil passou recentemente. Uma característica deste processo foi a supressão de modelos referenciais para organizar a vida pessoal, familiar e social e a consequente valorização do indivíduo e de suas experiências.

Historicamente a religião forneceu os modelos de pai, mãe, filho, assim como os parâmetros para julgamento do que é certo ou errado e do que é bom ou mau.

Para a Educação é relativamente tranquilo trabalhar em função destes modelos previamente definidos, mas Freire adverte que "o educador comprometido com a construção de um projeto político transformador constrói sua docência voltada para a autonomia do educando, valorizando e respeitando a sua cultura, o seu acervo de conhecimentos e sua individualidade" (FREIRE, 1977a).

A Educação, mais do que qualquer outra área de conhecimento, aprendeu a trabalhar com a diversidade, gerando respostas que contemplam quase todo o espectro das necessidades educacionais diferenciadas (indígena, quilombola, gênero, opção sexual, deficiências, estrangeiros, hospitalizados etc.). Paulo Freire tratou da questão da diferença em Pedagogia da Indignação (2000), fazendo a defesa do multiculturalismo, no qual o direito de ser diferente em uma sociedade dita democrática, enquanto uma liberdade conquistada de cada cultura, também deve proporcionar um diálogo crítico entre as diversas culturas, com o objetivo de consolidar e ampliar os processos de emancipação.

Portanto, na ausência de modelos únicos, hegemônicos e culturalmente impostos cabe à comunidade, juntamente com a escola pública que a atende, definir de comum acordo o perfil do educando a ser formado.

As bases de um PPP coletivamente construído podem ser assim resumidas:

- que tipo de pessoas o Estado, a sociedade e a prisão querem formar?

- quais os recursos físicos, humanos e financeiros disponibilizados para a escola?

- como serão organizados os processos de ensino/aprendizagem, monitoramento e avaliação do projeto político pedagógico?

Cada Estado brasileiro possui conjunturas específicas tanto na Educação quanto no seu sistema penitenciário, mas há documentos de referência que podem subsidiar a formulação dos respectivos projetos. São eles:

1. Plano Estadual de Educação. Nos Estados em que ele existe é pertinente verificar se o mesmo faz alguma referência à Educação em prisões.

2. Plano Diretor do Sistema Penitenciário. Dentre suas 22 metas, merece atenção a Meta 15 (Educação e profissionalização), na qual se faz o detalhamento quanto ao nível de escolaridade de toda a população prisional no Brasil. 
3. Plano Operativo Estadual de Saúde no Sistema Penitenciário. Desdobramento do Plano Nacional de Saúde no Sistema Penitenciário, que coloca a atenção à saúde do preso como atribuição do Sistema Único de Saúde (SUS).

4. Deliberações do Conselho Estadual de Educação sobre a oferta da Educação em Prisões ou, analogamente, sobre Educação de Jovens e Adultos e Educação Técnica e Profissional.

Observada a diretriz que determina ser a Educação em prisões obrigação do Estado por meio da articulação entre as secretarias que cuidam das prisões e da Educação, uma primeira definição a se fazer é quanto à forma de organização do sistema de ensino para atender as unidades prisionais.

O Mato Grosso do Sul, por exemplo, que iniciou a elaboração coletiva do seu plano estadual mesmo antes da homologação das Diretrizes Nacionais, atende 21 de suas 44 unidades prisionais por meio da Escola Estadual Pólo Profa. Regina Lúcia Anffe Nunes Betine, criada em Dezembro de 2003.

Esta escola está credenciada pelo Conselho Estadual de Educação para oferecer todas as modalidades da Educação Básica, possui um quadro próprio de 60 professores e cinco coordenadores pedagógicos e cada unidade prisional atendida é concebida como uma extensão da escola. Este é o modelo que podemos chamar de escola vinculadora ou escola pólo.

O Estado de Santa Catarina, não obstante possuir desde 1975 uma denominada Escola Supletiva Penitenciária, faz o atendimento escolar da população prisional por meio dos seus 36 Centros de Educação de Jovens e Adultos (CEJAs), diretamente subordinados a uma coordenadoria da Secretaria Estadual de Educação. Não obstante haver uma coordenação única para os 36 CEJAs, resguarda-se a autonomia de cada um na elaboração do seu PPP, caracterizando-se como um modelo descentralizado de atendimento.

No Mato Grosso existe desde 2009 a Escola Estadual Nova Chance, vinculada à Secretaria Estadual da Educação, que atende 19 das 60 unidades prisionais do Estado. Esta escola também se caracteriza como uma escola vinculadora e as unidades prisionais atendidas são concebidas como salas anexas da escola oficial.

Há ainda a possibilidade de que cada unidade prisional esteja diretamente vinculada à unidade escolar mais próxima ou que cada unidade prisional tenha sua própria escola, inclusive dotada das respectivas instituições auxiliares como grêmio, Conselho de Escola e Associação de Pais e Mestres.

Nos três estados aqui referenciados o Plano Estadual de Educação em Prisões foi concebido como as diretrizes estaduais para o tema, articulando secretarias e órgãos de governo; criando infraestrutura e logística; organizando as carreiras profissionais; estabelecendo atribuições 
e competências e organizando as condições de oferta, fiscalização e avaliação da Educação nas prisões.

O projeto político pedagógico constitui o instrumento operacional por meio do qual a Escola Regina Betine, os CEJAs e a Escola Nova Chance definiram suas prioridades, objetivos e metas a serem alcançadas em determinado período de tempo. O modelo da escola vinculadora ou escola pólo possibilita que o PPP seja único para todo o Estado, abrangendo a totalidade das unidades prisionais atendidas.

Importante ressaltar que no âmbito de um plano estadual não há uma solução única para oferta da Educação em prisões.

Quando analisados os dados relativos ao perfil de escolarização da população prisional no Brasil, a alfabetização surge como um desafio ético a ser enfrentado pelo Estado e pela sociedade, pois inadmissível hoje a existência de analfabetismo entre jovens e adultos em sociedades contemporâneas. A elevação da escolaridade para cerca de $80 \%$ dos presos que não concluíram o Ensino Fundamental soa como uma ação reparadora face ao fato de ter sido negado a eles o Direito à Educação na idade apropriada.

Durante o processo de elaboração dos planos estaduais para a Educação em estabelecimentos penais nos estados de Mato Grosso do Sul, Santa Catarina e Mato Grosso, a análise dos dados de escolarização dos presos apontaram para a necessidade de que a Educação de Jovens e Adultos a ser oferecida assumisse modelagens diversas para atender às diferentes necessidades de homens e mulheres presos.

A primeira modelagem, para contemplar os presos que não são alfabetizados ou não exercitaram o direito constitucional à Educação Básica de nove anos foi, prioritariamente, nos sentidos de alfabetização e de elevação da escolaridade.

Cruzados os dados de escolaridade e de trabalho, entretanto, ficou evidente que são exatamente estes os presos que mais constantemente optam pelo trabalho em detrimento da Educação, por razões óbvias. Logo, a proposta de Educação para este contingente teve que, inexoravelmente, considerar a relação trabalho e Educação, possibilitada pelo conceito de "qualificação pelo trabalho" enunciado no Artigo 27, Inciso III, combinado com o Artigo $37, \S 2^{\circ}$ da LDB que autoriza, inclusive, o reconhecimento de conhecimentos e habilidades adquiridos por meios informais.

A segunda modelagem contemplou os que possuem o Ensino Fundamental completo, portanto exercitaram o direito constitucional à escolarização básica de nove anos, mas devem 
ser estimulados à continuidade dos estudos com vistas à elevação, não apenas da escolaridade, mas também de suas competências técnicas relacionadas ao trabalho.

Os artigos 35, 36 e 41 da LDB autorizam o atendimento desta demanda por meio do Ensino Médio, no qual também podem ser aproveitados os conhecimentos e habilidades anteriormente adquiridos, resultando em certificação de Educação Profissional de Nível Médio com validade nacional e em uma profissão para o indivíduo quando em liberdade.

Uma terceira modelagem objetivou atender os presos que começaram, mas não concluíram o Ensino Médio e que, não obstante isso, exercem no interior da prisão ofícios indexados na Classificação Brasileira de Ocupações (CBO). O Artigo 40 da LDB autoriza diferentes articulações da Educação Profissional, inclusive com o próprio ambiente de trabalho. A ênfase, neste caso, foi estimular a conclusão desta etapa, explorando as possibilidades também previstas nos artigos 39, 41 e 42 da LDB.

Os presos que possuem o Ensino Médio Completo podem se beneficiar da Educação Profissional, estes sim, no sentido de aprendizagem de uma profissão de nível técnico, como são os casos dos monitores de Educação ( $\$ 2^{\circ}$ do Artigo $9^{\circ}$ das Diretrizes) e do Agente Prisional de Saúde (Art. $9^{\circ}$ da Portaria Interministerial 1777, de 9.9.2003 que institucionaliza o Plano Nacional de Saúde no Sistema Penitenciário). Este Plano prevê a qualificação profissional de pelo menos 5\% dos presos como Agentes Prisionais de Saúde, com formação equivalente ao do Agente Comunitário de Saúde.

Somente o uso destes dois dispositivos possibilita formar, de imediato, 25 mil presos para ajudar a enfrentar os graves problemas de saúde no sistema penitenciário. Usada a analogia e a mesma proporção para formação de presos como monitores de Educação seriam outros 25 mil auxiliares para os profissionais da Educação. Dadas as características que fazem com que a Saúde e a Educação possuam alto valor agregado na reabilitação e que os presos possuem, de modo geral, uma boa representação social destas profissões, mesmo quando exercida por outros presos, estas são duas profissões sociais de nível técnico capazes de impactar positivamente a cultura prisional, inclusive na formação de lideranças positivas dentre a população prisional.

Estas possibilidades estão regulamentadas no Catálogo Nacional de Cursos Técnicos (MEC, 2004) e as Diretrizes Nacionais fazem menção à "preparação especial" (formação pedagógica) que devem receber os presos para atuação no apoio aos profissionais da Educação, servindo a mesma orientação em relação aos profissionais da saúde.

Silva, Oliveira e Moreira apresentaram no artigo intitulado Ciência, trabalho d Educação no sistema prisional brasileiro (2016) 
Todos os profissionais designados para prestar as assistências e os serviços estipulados pela Lei de Execução Penal, com exceção da assistência religiosa, são funcionários do Estado, inclusive os professores e instrutores de ofícios na Educação Técnica e Profissional. Essa conjunção de conhecimentos e de profissionais de diversas áreas de atuação em um mesmo campo de trabalho possibilita configurar o que Thomas Kuhn, no livro A Estrutura das Revoluções Científicas, denomina comunidade científica, com a seguinte definição:

Uma comunidade científica é formada pelos praticantes de uma especialidade científica. Estes foram submetidos a uma iniciação profissional e a uma educação similares, numa extensão sem paralelo na maioria das outras disciplinas. Neste processo, absorveram a mesma literatura técnica e retiraram dela muitas das mesmas lições. (KUHN, 1998, p. 220).

O tamanho e a complexidade do sistema penitenciário brasileiro apontam para alguns desafios que não podem ser enfrentados apenas pela Execução Penal. Como reverter a tradição punitivista da pena e da prisão para concebê-las em sua dimensão educacional e pedagógica? Como descontruir a "pedagogia do crime" que impera no interior das prisões? Como fazer para que todos os profissionais que trabalham na prisão assumam as tarefas de Educação e de reabilitação do preso para o convício social? E, finalmente, como fzer pra que todas as ações e atividades desenvolvidas na prisão durante o cumprimento da sentença se constituam em meios de avaliação quanto à eficácia da terapia penal?

\section{Conclusão}

Como se depreende dos objetivos deste artigo, a Educação pode impactar e influenciar positivamente a Execução Penal, desde que cumpridas as determinações da Resolução CEB/CNE $n^{\circ} 2$ de que a Educação seja atribuição conjunta das secretarias de Educação e da Administração Penitenciária e que estas criem as estruturas necessárias para viabilizar, de parte a parte, a infraestrutura, a reforma dos regimentos internos, a elaboração de um projeto político pedagógico e a qualificação técnica e profissional de todos os atores envolvidos.

O Conselho Nacional de Política Criminal e Penitenciária (CNPCP) e o Departamento Penitenciário Nacional (DEPEN), por meio da Resolução no 9, de 18 de Novembro de 2011, haviam aprovado uma ambiciosa proposta intitulada Programa arquitetônico: Módulo base Projeto Referência, com orçamento aprovado e projetos de arquitetura e de engenharia já em estado adiantado, como proposta para dotar as unidades prisionais brasileiras de módulos de Educação e de Trabalho, inclusive com construções novas, que 
Em 12 de Abril de 2018, possivelmente por pressões dos governadores de estados, o mesmo CNPCP editou a Resolução No 2 autorizando a a flexibilização das Diretrizes Básicas para Arquitetura Penal antes aprovadas, deixando a critério dos estados construírem ou não os módulos de Educação e de Trabalho, o que significou o esvaziamento da proposta original.

$\mathrm{Na}$ tese de doutoramento intitulada A eficácia sociopedagógica da pena e privação da liberdade (SILVA, 2001) descrevi em minucias a pedagogia do crime, seus elementos constituintes e suas formas de reprodução dentro da prisão, destacando que,

Com a proposta de deslindar os elementos constitutivos de uma suposta pedagogia do crime, à Pedagogia e ao pedagogo importam entender a sistemática de interação entre os internos, que faz com que o indivíduo construa, incorpore e reafirme continuamente uma identidade negativa, e os mecanismos subliminares que fazem da prática delituosa mais como um recurso de afirmação da personalidade negativa do que como um recurso de prática da delinquência propriamente dita (SILVA, 2001, p. 25).

Retomando os três eixos orientadores das Diretrizes Nacionais para a oferta da Educação em Estabelecimentos Penais - 1. Gestão, Articulação e Mobilização; 2. Formação e valorização dos profissionais envolvidos na oferta; 3 . Aspectos pedagógicos - não restam dúvidas de que a cultura prisional precisa ser enfrentada de forma sistêmica em todas as suas dimensões.

A eficácia da pena de privação da liberdade é analisada em função dos objetivos propostos em lei, orientando-se por dois fatores que se revelaram preponderantes após a tabulação dos dados: a) à vulnerabilidade pessoal e social de quem é a ela submetido, sobretudo diante dos efeitos deletérios da pedagogia do crime e; b) ao modelo de administração penitenciária, sustentada por um tripé cujos elementos estruturais são: 1) a permissividade para ocorrência do tráfico de drogas; 2) a permissividade para a corrupção entre alguns poucos funcionários, como forma de amenizar o rigor e os riscos do trabalho e os baixos salários pagos e; 3) a compra e venda de privilégios na relação entre presos e alguns funcionários, todos propiciando a existência, manutenção e reprodução de uma cultura prisional que norteia a natureza das relações internas entre presos e entre presos e funcionários. (SILVA, 2001, p. 05)

Pelas razões e argumentos expostos neste artigo e diante da revogação da Resolução CNPCP $\mathrm{n}^{\circ}$ 9, e a falta de infraestrutura escolar nas unidades prisionais brasileiras, chegamos à conclusão que dentre os modelos adotados pelos estados brasileiros para a oferta da Educação em prisões, a Escola Penitenciária é a que oferece melhores condições para ter um Projeto Político Pedagógico próprio e específico para a população prisional.

Por Escola Penitenciário estamos nos referindo a uma unidade escolar com identidade jurídica própria, dotada de direção e de equipe pedagógica próprias, com o respectivo quadro 
docente que, usando as prerrogativas dos artigos 37,39, 81 da LDB, possa construir coletivamente o seu próprio projeto político pedagógico, considerando, como é característico deste instrumento, todos os serviços e os recursos físicos, materiais, humanos e financeiros existentes na prisão.

Diferentemente de outras políticas públicas em que se privilegia o atendimento do cidadão por meio de órgãos e serviços públicos existentes na comunidade local, a oferta de Educação para pessoas privadas da liberdade constitui uma das poucas exceções que justifica a oferta deste direito dentro da própria unidade prisional, por força da restrição do direito de ir e vir previsto na sentença de condenação.

É esta conjuntura que levou o GEPÊPRIVAÇÃO a reafirmar seu posicionamento expresso no livro Didática no Cárcere II (SILVA, 2018, p. 17), que qualquer proposta educacional para as prisões brasileiras deve levar em consideração estes fatores:

- deficiências de infraestrutura (sala, carteiras, lousas, equipamentos etc.);

- falta de material didático específico e restrições ao uso de materiais convencionais de uso comum

- salas com pessoas de diferentes idades

- grande defasagem na relação idade/série

- classes multisseriadas

- excessiva rotatividade dos alunos

- rígidos sistemas disciplinares que impedem livre movimentação dos alunos

- rígidos sistemas de segurança que dificultam o acesso e movimentação de professores

- dificuldade de acesso a recursos de TIC (Tecnologias da Informação e da Comunicação)

- precariedade de estímulos sensoriais (visual, auditivo, tátil, gustativo e olfativo)

Os diferenciais deste PPP são as possibilidades de incorporação do conceito de comunidade científica tal qual enunciado por Thomas Khun (KHUN, 1998) para agregar todas as ciências e seus respectivos profissionais em torno de objetivos comuns e de articular a educação escolar com a educação não escolar e as demais atividades de trabalho, esporte, arte, cultura, saúde e as assistências jurídica, psicológica, social e religiosa em um mesmo projeto, além de desenvolver seu próprio material didático pedagógico e proporcionar formação de seus professores segundo os pressupostos teóricos e metodológicos do seu PPP.

A opção por este modelo tem a ver também com o aproveitamento do potencial que oferecem os artigos 37,38 e 81 da LDB.

Art. $37-\S 1^{\circ}[\ldots]$ oportunidades educacionais apropriadas, consideradas as características do alunado, seus interesses, condições de vida e de trabalho. $\S 2^{\circ}[\ldots]$ o acesso e a permanência do trabalhador na escola, mediante ações integradas e complementares entre si. 
$\S 3^{\circ}[\ldots]$ articular-se, preferencialmente, com a educação profissional.

Art. 38 - $\S 2^{\circ}$ Os conhecimentos e habilidades adquiridos pelos educandos por meios informais serão aferidos e reconhecidos mediante exames.

Art. 81 - Art. 81. É permitida a organização de cursos ou instituições de ensino experimentais, desde que obedecidas as disposições desta Lei.

Por analogia, o Conselho da Comunidade e o Patronato, previstos no Artigo 61, VI e VII da Lei de Execução Penal são instituições auxiliares do estabelecimento penitenciário e podem cumprir as funções determinadas no Artigo 14, II da LDB para efeito de cumprimento do preceito da gestão democrática previsto no Artigo 15 da mesma Lei, inclusive para execução dos programas suplementares a que se refere o Artigo $4^{\circ}$, VII da LDB e administração de seus próprios recursos financeiros, como Caixa Escolar, conforme dispõe o Artigo 12, II da mesma LDB.

Como se depreende das análises aqui realizadas, o atendimento às especificidades da Educação no sistema prisional brasileiro não cabe na estrutura e na forma de organização e de funcionamento de uma escola regular tal qual as que atendem a rede pública de ensino para atendimento à comunidade livre.

Finalmente considera-se que professores e professores devam ter dedicação exclusiva a esta modalidade de ensino, como uma especialidade na carreira do magistério, seleção por meio de concurso público e direito às prerrogativas relativas ao trabalho perigoso e insalubre, de acordo com o previsto no Artigo $7^{\circ}$, XXIII na Constituição Federal que determina que seja pago "adicional de remuneração para as atividades penosas, insalubres ou perigosas, na forma da lei".

\section{Referências}

BRASIL. Lei de Execução Penal. Lei Federal nº 7.210, de 11.7.1984.

BRASIL. Lei de Diretrizes e Bases da Educação Nacional. Lei 9394, de 20.12.1996.

Cne. Resolução CNE/CEB n ${ }^{\circ}$, de 20 de maio de 2010. Institui as Diretrizes nacionais para a oferta de Educação para jovens e adultos em estabelecimentos penais.

Cnpcp. Resolução No 3, de 11 de março de 2009. Conselho Nacional de Política Criminal e Penitenciária. Dispõe sobre as Diretrizes Nacionais para a Oferta de Educação nos estabelecimentos penais.

CNPCP. Resolução N 9, de 18 de Novembro de 2011. Institui as Diretrizes Básicas para Arquitetura Penal. D.O.U de 21 de Novembro de 2011, No 222, Seção 1, pág. 79).

CNPCP. Resolução N 2, de 12 de Abril de 2018. Dispõe sobre a flexibilização das Diretrizes Básicas para Arquitetura Penal. DOU de 7 de maio de 2018, No 86, Seção I, p. 79.

FREIRE, Paulo. A Educação na Cidade. $5^{\text {a }}$ edição. São Paulo: Cortez, 2001a. 
KHUN, Thomas. A Estrutura das Revoluções Científicas. 5ª ed. São Paulo: Perspectiva, 1998.

MEC. Catálogo Nacional de Cursos Técnicos. Brasília/DF: MEC/SECAD, 2004.

ONU. Resolução nº . 45/110, de 14 de Dezembro de 1990. Institui as Regras Mínimas para a Elaboração de Medidas não Privativas de Liberdade.

SILVA, Roberto da. A eficácia sociopedagógica da pena de privação da liberdade. Tese de Doutorado (Programa de Pós-Graduação em Educação da Universidade de São Paulo). São Paulo: FEUSP, 2001.

SILVA, Roberto da; MOREIRA, Fábio Aparecido. Objetivos educacionais e objetivos da reabilitação penal: o diálogo possível. IN: Dossiê Questões Penitenciárias. Revista Sociologia Jurídica. n. 03. Julho/Dezembro de 2006.

SILVA, Roberto da; OLIVEIRA, Carolina Ferreira Bessa de; MOREIRA, Fábio Aparecido. Ciência, trabalho e Educação no sistema penitenciário brasileiro. Cad. Cedes, Campinas, v. 36, n. 98, p. 9-24, jan.-abr., 2016.

SILVA, Roberto da. Didática no Cárcere II. São Paulo: Giostri, 2018.

Recebido em: 11 de janeiro de 2021.

Publicado em: 20 de abril de 2021. 